\title{
Study between axillary and rectal temperature measurements in children
}

\author{
R.B. Haddadin ${ }^{1}$ and H.I. Shamo'on ${ }^{1}$
}

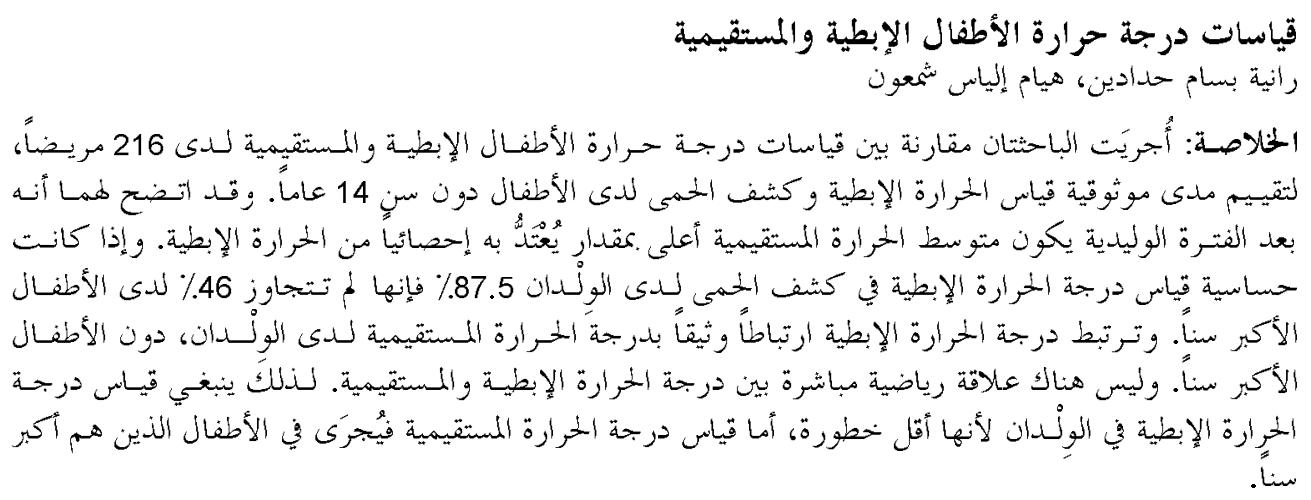

ABSTRACT We compared axillary and rectal temperatures in 216 patients to assess the reliability of axillary temperature for determining fever in children under 14 years of age. Beyond the neonatal period, the mean rectal temperature was significantly higher than the axillary temperature. The sensitivity of axillary temperature in detecting fever was $87.5 \%$ among neonates but only $46 \%$ among older children. Axillary temperature correlated well with rectal temperature in neonates but not older children. There was no direct mathematical relationship between axillary and rectal temperature. Axillary temperature should be taken in neonates as it is less hazardous; rectal temperature should be used beyond this age.

Étude comparative température axillaire versus température rectale chez l'enfant

RÉSUMÉ Nous avons comparé les températures axillaire et rectale chez 216 patients afin d'évaluer la fiabilité de la mesure de la température axillaire pour déterminer la fièvre chez l'enfant de moins de 14 ans. Au-delà de la période néonatale, la température rectale moyenne s'est avérée significativement supérieure à la température axillaire. La mesure de la température axillaire a fait preuve d'une sensibilité de détection de la fièvre de $87,5 \%$ chez les nouveau-nés contre seulement $46 \%$ chez les enfants plus âgés. II n'est apparu aucune relation mathématique directe entre les températures axillaire et rectale. La température axillaire doit être réservée au nouveau-né pour lequel cette mesure est moins aléatoire, la température rectale devant lui être préférée au-delà de cet âge. 


\section{Introduction}

The presence of fever in children and neonates affects the decision of both parents and clinicians [1]. Parents may get worried and take vigorous steps to lower their child's temperature before and after seeking medical advice $[1,2]$. Clinicians, on the other hand, may carry out unnecessary investigations, interventions, and depending on the age of the patient and his/her temperature, may admit the child to hospital $[1,3]$ or just send him/her home with or without antibiotics. Usually the cut-off point, especially in children below 6 months, is $38.3^{\circ} \mathrm{C}[4,5]$.

Measuring temperature in children can be difficult, especially when they are uncooperative or restless [1]. Measuring rectal temperature is frequently preferred over other ways but may be unacceptable to older children and their parents $[1,6]$. The axilla is a safe and accessible site but concerns have been raised about its accuracy $[1,7,8]$ and its correlation with core temperature $[9,10]$.

The objectives of this study were to evaluate the agreement between temperature measured at the axilla and that measured in the rectum in children and young people, using a conventional glass mercury thermometer, to find if there is a direct mathematical relationship between axillary and rectal temperature, and to determine the optimum time for insertion of the thermometer.

\section{Methods}

Our study was carried out at Queen Alia Military Hospital in Amman over a period of 1 year (June 2001-May 2002). It included 216 patients from birth to 14 years of age consecutively selected from children presenting with history of fever to the children's clinic or paediatric emergency clinic of the hospital; 87 (40.3\%) were females. Children with hypothermia (rectal temperature $<35^{\circ} \mathrm{C}$ ) and premature babies (gestational age $<37$ weeks) were excluded from the study (13 children). Consent was obtained from the parent(s) after explaining the study to them.

The patients were divided into 7 groups according to age as follows:

- Group 1: 0-30 days (20 children; 50\% were females).

- Group 2: 31 days-3 months (19 children; $57.9 \%$ were females).

- Group 3:>3 months-6 months (12 children; $2.4 \%$ were females).

- Group 4: > 6 months-1 year (30 children; $23.3 \% \%$ were females).

- Group 5: > 1 year-3 years (60 children; $40 \%$ were females).

- Group 6: $>3$ years-6 years (44 children; $45.5 \%$ were females).

- Group 7: > 6 years-14 years (31 children; 41.9\% were females).

In Queen Alia Military Hospital, rectal temperature is usually taken in those less than 3 years while axillary temperature is taken in children over this age. In each patient, the axillary temperature was measured first and then the rectal temperature before examination of the patient or any medical intervention. A standarized calibrated medical mercury thermometer was used and held in place for at least 5 minutes for each temperature measurement. The rectal temperature stabilization time was reached in less than 3 minutes, but not all the axillary temperatures reached a stabilization by 5 minutes and we kept the thermometer in place for up to 9 minutes in those whose temperature did not stabilize; thus 5 minutes, was selected for practical reasons. The temperature was recorded 5 times at 1 minute intervals after 2 minutes of insertion. 
Thermometers were calibrated before each measurement. The calibration was done using a special thermometer calibration system (ERTCO, TCS100, Dubuque, USA) based on a method given in NIST monograph 150 with total accuracy \pm $0.2{ }^{\circ} \mathrm{C}$. All temperature measurement were made by one of the researchers

Statistical analysis was carried out by the SAS system (general linear models procedures) [11], in which analysis of variance and correlation coefficients of both methods of measurement were calculated. Also, the median, mean, standard deviation (SD), specificity and sensitivity were calculated for each age group.

\section{Results}

Table 1 shows the sensitivity of the axillary method using the rectal method as the gold standard in the different age groups. While, the sensitivity in the neonatal group was $87.5 \%$, it dropped considerably in the older age groups.

The mean of axillary temperature was found to be lower than the rectal temperature as shown in Table 2. The mean and median temperatures of both methods of temperature measurement in the different age groups are shown in Tables 2 and 3 . As the age increased, the mean differences between the 2 methods increased (Tables 2 and 3, Figure 1).

The validity of temperature readings at both sites was related to the child's age and the duration of contact of the child with the measuring device as it was noticed that $100 \%$ of rectal temperature readings stabilized at 3 minutes with a mean of 2.2 minutes (SD 0.42), while $93 \%$ of axillary readings stabilized at 5 minutes and $98 \%$ at 7 minutes with a mean of 4.4 minutes (SD 0.84) (Table 4).

Analysis of variance showed no significant differences due to sex while age group and method of measurement gave significant differences $(P<0.01)$. The correlation coefficient between axillary and rectal methods was $0.92(P<0.01)$ for the neonatal group while the other values decreased as age increased (Table 5). This result indicates that both methods of temperature measurement can give similar assessment of body temperature at younger age but this agreement decreased with age. The coefficients of

\begin{tabular}{|c|c|c|c|c|c|}
\hline Age group & $\begin{array}{c}\text { Febrile patients } \\
\text { detected by } \\
\text { axillary method } \\
\text { No. }\end{array}$ & $\begin{array}{l}\text { Febrile patients } \\
\text { detected by } \\
\text { rectal method } \\
\text { No. }\end{array}$ & $\begin{array}{c}\text { Afebrile } \\
\text { patients } \\
\text { No. }\end{array}$ & $\%$ & Specificity \\
\hline $0-30$ days & 7 & 8 & 12 & 87.5 & 100 \\
\hline $\begin{array}{l}31 \text { days }-3 \\
\text { months }\end{array}$ & 4 & 7 & 12 & 57.1 & 100 \\
\hline$>3-6$ months & 5 & 8 & 4 & 62.5 & 100 \\
\hline $\begin{array}{l}>6 \text { months }-1 \\
\text { year }\end{array}$ & 6 & 17 & 13 & 35.3 & 100 \\
\hline$>1-3$ years & 21 & 40 & 20 & 52.5 & 100 \\
\hline > 3-6 years & 5 & 20 & 22 & 25.0 & 100 \\
\hline$>6-14$ years & 12 & 23 & 8 & 52.2 & 100 \\
\hline
\end{tabular}




\begin{tabular}{|c|c|c|c|}
\hline Age group & $\begin{array}{c}\text { Mean axillary } \\
\text { temperature (SE) } \\
{ }^{\circ} \mathrm{C}\end{array}$ & $\begin{array}{c}\text { Mean rectal } \\
\text { temperature (SE) } \\
{ }^{\circ} \mathrm{C}\end{array}$ & $\begin{array}{c}\text { Mean } \\
\text { difference (SE) } \\
{ }^{\circ} \mathrm{C}\end{array}$ \\
\hline $0-30$ days & $37.7(0.3)$ & $38.1(0.3)$ & $0.52(0.03)$ \\
\hline $\begin{array}{c}31 \text { days }-3 \\
\text { months }\end{array}$ & $37.3(0.1)$ & $37.9(0.2)$ & $0.67(0.03)$ \\
\hline$>3-6$ months & $37.9(0.5)$ & $38.8(0.3)$ & $1.04(0.1)$ \\
\hline$>6$ months -1 & & & \\
\hline year & $37.4(0.2)$ & $38.3(0.2)$ & $1.02(0.03)$ \\
\hline$>1-3$ years & $37.5(0.2)$ & $38.7(0.1)$ & $1.17(0.03)$ \\
\hline$>3-6$ years & $36.9(0.2)$ & $38.0(0.1)$ & $1.06(0.02)$ \\
\hline$>6-14$ years & $37.4(0.2)$ & $38.0(0.2)$ & $1.26(0.04)$ \\
\hline
\end{tabular}

The mean rectal temperature was significantly higher than the axillary temperature in age group 2 and over $(P<0.001)$.

$S E=$ standard error of the mean.

variations for the 2 methods are presented in Table 6 and indicate very accurate temperature measurement during the study.

\section{Discussion}

Body temperature has long been regarded as a vital sign of physiological integrity and, as such, has been assessed by numerous methods across centuries [9]. It follows a circadian rhythm being lowest at 06:00 $[4,11]$. It is used in the context of other data to determine both the presence of illness and the extent to which a patient is responding to treatment.

It is well known that the best site for measuring temperature is near the temperature regulating centre and this is called the core temperature, i.e. pulmonary artery, oesophagus, bladder [4,12-14], but these are impractical for routine use [15]. The closest alternative sites are body cavities near large vessels, e.g. oral, rectal, aural $[9,16]$. Numerous researchers have documented that rectal temperature significantly lags behind measured changes at other core sites, especially during acute temperature fluctuation and changes [13]. In addition, obtaining a rectal temperature is timeconsuming and poses the risk of perforation [10]. Although measurement of axillary temperature is easily accomplished and is not painful or distressing $[11,12]$, it does not correlate well with core temperature $[9,10]$. This inaccuracy renders the axillary method

\begin{tabular}{|c|c|c|c|}
\hline Age group & Median & $\begin{array}{l}\text { Standard } \\
\text { deviation }\end{array}$ & $\begin{array}{l}\text { Coefficient } \\
\text { of variation }\end{array}$ \\
\hline & ${ }^{\circ} \mathrm{C}$ & ${ }^{\circ} \mathrm{C}$ & \\
\hline $0-30$ days & 0.4 & 0.13 & 0.24 \\
\hline \multicolumn{4}{|l|}{31 days-3 } \\
\hline$>3-6$ months & 0.85 & 0.35 & 0.33 \\
\hline \multicolumn{4}{|l|}{$>6$ months -1} \\
\hline year & 1.0 & 0.16 & 0.16 \\
\hline$>1-3$ years & 1.2 & 0.20 & 0.17 \\
\hline > 3-6 years & 1.1 & 0.16 & 0.15 \\
\hline$>6-14$ years & 1.2 & 0.20 & 0.16 \\
\hline
\end{tabular}




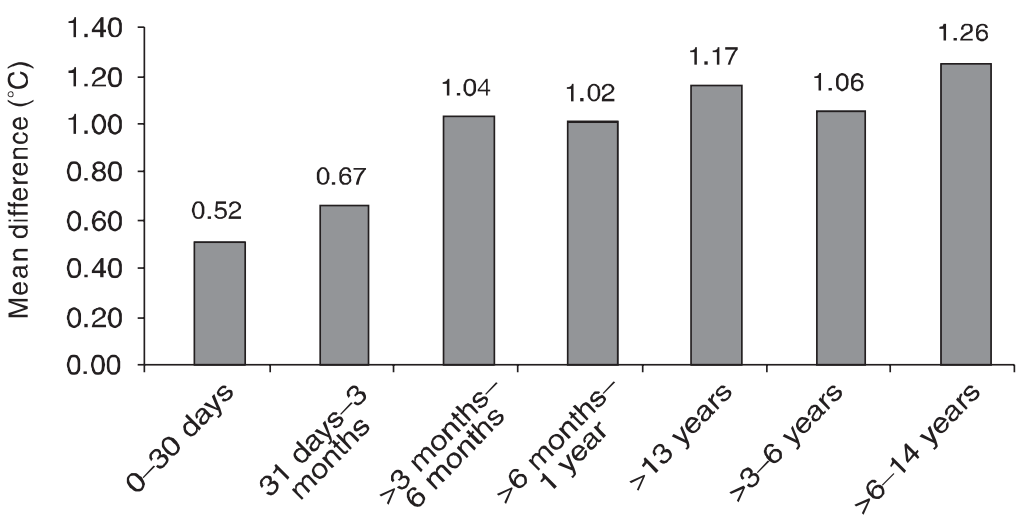

Figure 1 Mean difference in temperature between the two methods of measurement by age group

an unacceptable method of measurement, especially in critical care settings.

Determining febrile status is very important in assessment of patient's status, and accurate measurement of temperature is required in certain clinical situations or age groups, for example in neutropenic patients, whether to start antibiotics or not $[1,7,17]$ depends on accurate temperature measurement, and also in neonates for insuring a thermoneutral state.

\begin{tabular}{lcc}
\hline $\begin{array}{l}\text { Table } 4 \text { Time taken for stabilization of } \\
\text { temperature measurements by site of } \\
\text { measurement }\end{array}$ \\
\hline Time (minutes) & $\begin{array}{c}\text { Site of measurement } \\
\text { Rectal } \\
\text { No. of } \\
\text { patients }\end{array}$ & $\begin{array}{c}\text { Axillary } \\
\text { No. of } \\
\text { patients }\end{array}$ \\
\hline 2 & 200 & 33 \\
3 & 16 & 58 \\
4 & - & 90 \\
5 & - & 19 \\
6 & - & 10 \\
7 & - & 2 \\
\hline aln 4 patients the temperature measurement did not \\
stabilize.
\end{tabular}

We studied the classic mercury glass thermometer because it is the most widely used device in our country and most developing countries, because of its reasonable price in comparison with electronic and disposable chemical methods, and because it is the most suitable for use in hospitalized patients $[18,19]$.

It is believed that rectal temperature can be estimated by adding $0.5^{\circ} \mathrm{C}$ to the temperature measured at the axilla, but in

Table 5 Correlation coefficient between axillary and rectal methods for each age group

\begin{tabular}{lc}
\hline Age group & Correlation coefficient \\
\hline $0-30$ days & $0.92^{* *}$ \\
31 days -3 months & $0.81^{* *}$ \\
$>3-6$ months & $0.86^{* *}$ \\
$>6$ months-1 year & $0.87^{* *}$ \\
$>1-3$ years & $0.74^{*}$ \\
$>3-6$ years & $0.79^{*}$ \\
$>6-14$ years & $0.74^{*}$ \\
\hline${ }^{*}$ Significant at $\mathrm{P}<0.05$. & \\
${ }^{* *}$ Significant at $\mathrm{P}<0.01$. &
\end{tabular}




\begin{tabular}{|c|c|c|}
\hline Age group & $\begin{array}{l}\text { CV for axillary } \\
\text { method (\%) }\end{array}$ & $\begin{array}{l}\text { CV for rectal } \\
\text { method (\%) }\end{array}$ \\
\hline $0-30$ days & 3.15 & 3.18 \\
\hline 31 days -3 months & 2.19 & 2.64 \\
\hline$>3-6$ months & 4.26 & 2.33 \\
\hline$>6$ months -1 year & 3.37 & 2.77 \\
\hline$>1-3$ years & 3.23 & 2.69 \\
\hline$>3-6$ years & 2.76 & 2.26 \\
\hline$>3-6$ years & 2.91 & 2.86 \\
\hline
\end{tabular}

our study the wide range in the mean differences suggests that this is not the case. This finding is consistent with the study of Brown et al. who concluded that adding a correction factor to axillary readings is invalid [20].

Our study indicates a consistent relationship between axillary and rectal temperatures as there was a high and significant correlation between axillary and rectal temperatures, with the highest value $(0.92)$ in the case of neonates. The correlation tended to decrease with age. This result is in agreement with Schiffman who reported a significant positive correlation between axillary and rectal temperatures [21]. He concluded that axillary temperature taking may be a practical method for neonatal temperature monitoring. With regard to the heterogeneity between mean differences within groups, our results are similar to those of Craig et al. [1] who found significant heterogeneity between mean differences; the values for neonates and older children were 0.17 and
0.92 respectively. Thus axillary temperature in young children above neonatal age does not reliably reflect rectal temperature and should be interpreted with caution.

In our study, the temperature recorded at the axillary site could be almost the same as the rectal temperature or lower by $2.2^{\circ} \mathrm{C}$. The mean difference increased with increasing temperature sometimes reaching more than $2{ }^{\circ} \mathrm{C}$ with fever above $39^{\circ} \mathrm{C}$, especially in children past the neonatal age. This is consistent with Falzon et al. with regards to age but the differences were smaller [22].

Our finding that the sensitivity of the axillary method for neonates was quite high $(87.5 \%)$ while for older groups it was much lower is similar to that of Osinusi and Njinyam [23].

\section{Conclusion}

It can be concluded that, unlike in older children, axillary temperature in neonates correlates well with the rectal temperature and it is sensitive enough to detect fever. Thus, axillary rather than rectal temperature should be taken in neonates because it is safer and avoids the risk of rectal perforation. Rectal temperatures should be taken in older children especially in documenting low grade fever.

When axillary method is used, the thermometer should be left in place for at least 5 minutes.

There was no direct mathematical relationship between axillary and rectal temperature as has long been considered.

\section{References}

1. Craig JV et al. Temperature measured at the axilla compared with rectum in children and young people: systematic review. British medical journal, 2000,320:1174-8.
2. Schmitt BD. Fever phobia: misconceptions of parents about fever. Journal of diseases in children, 1980, 134:176-81. 
3. Thomas $\vee$ et al. National survey of pediatric fever management practices among emergency department nurses. Journal of emergency nursing, 1994, 20:505-10.

4. Powell KR. Fever. In: Behrman RE, Kliegman RM, Jenson HB, eds. Nelson textbook of pediatrics, 17th ed. Philadelphia, WB Saunders, 2004:839-46.

5. Siberry GK et al. Comparison of temple temperatures with rectal temperatures in children under two years of age. Clinical pediatrics, 2002, 41:405-14.

6. Sehgal A et al. Comparison of tympanic and rectal temperature in febrile patients. Indian journal of pediatrics, 2002, 69:305-8.

7. Keeley D. Taking infants' temperatures. British medical journal, 1992, 304:931-2.

8. Erickson RS, Woo TM. Accuracy of infrared ear thermometry and traditional temperature methods in young children. Heart \& lung: the journal of critical care, 1994, 23:181-95.

9. Giuliano KK, Scott SS. Temperature measurement in critically ill orally intubated adults: A comparison of pulmonary artery core, tympanic, and oral methods. Critical care medicine, 1999, 27:2188-94.

10. Schmitz $T$ et al. A comparison of five methods of temperature measurement in febrile intensive care unit patients. American journal of critical care, 1995, 4:286-92.

11. Lell B et al. The circadian rhythm of body temperature is preserved during malarial fever. Wiener klinische Wochenschrift, 2000, 112:1014-5.

12. Jean-Mary MB et al. Limited accuracy and reliability of infrared axillary and aural thermometers in pediatric outpatient population. Journal of pediatrics, 2002, 141:671-6.

13. Jaffe DM. What's hot and what's not: the gold standard for thermometry in emergency medicine. Annals of emergency medicine, 1995, 25:97-9.

14. Muma BK et al. Comparison of rectal, axillary, and tympanic membrane temperatures in infants and young children.
Annals of emergency medicine, 1991, $20: 41-4$

15. Robb PJ, Shahab R. Infrared transtympanic temperature measurement and otitis media with effusion. International journal of pediatrics and otorhinolaryngology, 2001, 59:195-200.

16. Androkites AL, Werger AM, Young ML. Comparison of axillary and infrared tympanic membrane thermometry in a pediatric oncology outpatient setting. Journal of pediatric oncology nursing, 1998, 15: 216-22.

17. Hughes WT, Armstrong D, Body GP. Guidelines for the use of antimicrobial agents in neutropenic patients with unexplained fever. Infectious diseases, 1990 , 161:381-96.

18. Ilsley AH, Rutten AJ, Runciman WB. An evaluation of body temperature measurement. Anaesthesia and intensive care, 1983, 11(1):31-9.

19. Gote $\mathrm{H}$ et al. Kan oral- eller aksiltemperatur erstatte rektal temperaturmaling [Can measurement of oral or axillary temperature replace the rectal temperature measurements]? Ugeskrift for laeger, 1989, 151:2085-7.

20. Brown PJ, Christmas BF, Ford RP. Taking an infant's temperature: axillary or rectal thermometer? Australian and New Zealand medical journal, 1992, 105:309-11.

21. Schiffman RF. Temperature monitoring in the neonate: a comparison axillary and rectal temperatures. Nursing research, 1982, 31:274-7.

22. Falzon A et al. How reliable is axillary temperature measurement? Acta paediatrica, 2003, 92:309-13.

23. Osinusi K, Njinyam MN. Comparison of body temperatures taken at different sites and the reliability of axillary temperature in screening for fever. African journal of medicine and medical sciences, 1997, 26:163-6. 